\title{
Ensino de Língua Inglesa na Educação Básica: Cultura e Vocabulário como portas (de abrir)
}

Vivian Albertoni*

Resumo: O artigo reflete a respeito da necessidade de incluir, nas aulas de Língua Estrangeira (especificamente, de Língua Inglesa), elementos culturais do idioma estudado. Os objetivos seriam a qualificação do estudo de vocabulário, a abertura de horizontes culturais e a superação de algumas resistências comuns em alunos do ensino básico.

Palavras-chave: Estudo de Língua Estrangeira; Educação Básica; Vocabulário; Estratégias de Ensino.

Abstract: The article proposes some research about the necessity of include, in Foreign Language classes (specially English language classes), cultural elements of the language. The goals would be the qualification of vocabulary study, the contact with new cultural horizons and the weakening of some typical difficulties the students present.

Keywords: Foreign Language studies; Basic Education; Vocabulary; Teaching strategies.

* Professora de Língua Portuguesa e Literatura no CAp/UFRGS. Doutora em Literatura Brasileira pela UFRGS. E-mail: vivianignes3@yahoo.com.br 
Para além da memorização mecánica de regras gramaticais ou das caracteristicas de determinado movimento literário, o aluno deve ter meios para ampliar e articular conbecimentos e competências [...]

$$
(\mathrm{PCN}+, 2002, \text { p. 55) }
$$

A arquitetura como construir portas, de abrir; ou como construir o aberto; construir, não como ilhar e prender, nem construir como fechar secretos; construir portas abertas, em portas; casas exclusivamente portas e teto.

O arquiteto: o que abre para o homem (tudo se sanearia desde casas abertas) portas por-onde, jamais portas-contra; por onde, livres: ar luz razão certa.

(João Cabral de Melo Neto ${ }^{1}$ )

\section{Introdução}

Quando se debatem as habilidades a serem desenvolvidas nas aulas de Língua Portuguesa, é ponto pacífico que se trata não só de saber aplicar regras gramaticais, mas também de interpretar textos dos mais diversos gêneros, produzir enunciados de forma oral e escrita, e compreender o contexto cultural que motiva as realizações linguísticas estudadas.

A razão de se tratar de um ponto pacífico é que, do ponto de vista contemporâneo, não se pode conceber um usuário competente de determinada língua que não possa utilizá-la como

Fábula de um arquiteto. Obra completa: volume único. Rio de Janeiro: Nova Aguilar, 1994 
instrumento de leitura do mundo, ou seja, que não seja capaz de perceber as questões semânticas e contextuais envolvidas nas produções linguísticas ${ }^{2}$.

O componente curricular Língua Portuguesa tradicionalmente inclui textos para estudo, o que permite não apenas o estudo de elementos gramaticais que envolvem a leitura e a interpretação, mas também cria situações de debate a respeito dos assuntos tratados. Em consequiência disso, é grande a diversidade de assuntos tratados pelo professor de Português em sala de aula.

Outro papel importante na tarefa de relacionar elementos culturais com o aprendizado da Língua é desempenhado pela Literatura. Os Parâmetros Curriculares Nacionais colocam a Literatura em um lugar de destaque, ao afirmarem a necessidade de utilizar a Literatura como espaço de expressão cultural de uma língua, estudando-a além dos aspectos estéticos (PCNs, 2002).

O ensino de Língua Materna possui preocupações - pertinentes - no que diz respeito à leitura de mundo, ainda que se possa concluir que o aluno já está imerso no universo cultural da língua que utiliza primariamente. A escola acaba se dedicando à instrumentalização dessa capacidade de leitura e interpretação, sensibilizando os alunos para a sua própria habilidade de realizar essa leitura - o que, a partir de certos níveis de ensino, chega a desvincular a competência na expressão escrita do domínio das regras da língua ${ }^{3}$.

Se o conceito de competência está relacionado à compreensão de enunciados em um nível além da gramaticalidade nos estudos de Língua Materna, poder-se-ia supor que é diretriz para o ensino de Língua Estrangeira, em especial porque nesse caso não se tem o ambiente cultural provedor de significados que se tem para a Lingua Materna.

2 Obviamente, o advento da Linguística moderna possui papel de destaque na valorização da competência.

3 Admite-se, portanto, que um usuário competente em seu idioma materno cometa erros em sua escrita, desde que esses erros não interfiram de forma determinante no objetivo desejado pelo emissor ao construir seu texto. 
Diante dessa observação, temos ao menos duas possibilidades:

a) trata-se de uma conclusão lógica a de que o ensino de LE deve priorizar a necessidade de conhecer elementos culturais da língua estudada, na mesma medida em que se preocupa com o arcabouço gramatical, uma vez que a linguagem é um recorte de mundo, e o aprendizado de vocabulário, por exemplo, quando não imerso no contexto de que provém, é falho;

b) o aluno deve ser instrumentalizado gramaticalmente, a fim de desenvolver habilidades básicas de leitura e escrita, ampliando seu vocabulário à medida em que lê e escreve na LE. Uma vez que qualquer recriação de contextos para fins de imersão cultural não passaria, justamente, de recriação, cabe confiar que a leitura e o contato com o idioma através de diferentes mídias será suficiente para prover um conhecimento vocabular adequado.

O vocabulário foi escolhido por nós justamente por ser um dos eixos nos quais os estudantes de Língua Inglesa mais apresentam dificuldades. Neste artigo, vamos debater a importância/ necessidade de montar aulas que sejam centradas na relação entre vocabulário e cultura, a fim de que os alunos compreendam a origem e o sentido de vocábulos e expressões utilizados pelos falantes da LE.

\section{Algumas palavras sobre o contexto de observação}

Esta docente tem experiência como professora de Língua Portuguesa em instituições de ensino públicas e particulares, e de apenas pouco mais de dois anos como professora de Língua Inglesa ${ }^{4}$; no entanto, na busca por parceiros para trabalhos

\footnotetext{
4 Desse tempo, são seis meses no CAp, que não devem contar para este artigo, pelas circunstâncias diferenciadas do ensino de LE na citada instituição. As demais escolas a serem utilizadas como comentário aqui são todas na região metropolitana de Porto Alegre - três estaduais e quatro particulares - e foram observadas entre os anos de 2006 e 2010.
} 
interdisciplinares, incluiu logo os colegas que lecionavam Língua Inglesa, conversou com eles sobre seu trabalho, e percebeu elementos comuns à forma como planejavam suas aulas.

Não importa a gerência da escola, existe forte cobrança para que a aula de LE seja um espaço para o aprendizado de vocabulário básico (na verdade, memorização e manuseio auxiliar de dicionário) e elementos de estrutura sintática. As atividades mais próximas à cultura são a leitura de textos selecionados (no livro didático, fotocopiados pelo professor e, modernamente, na Internet) e a assistência a filmes e programas de TV na $\mathrm{LE}^{5}$.

É importante ainda que se destaque a posição ocupada pela LE nas escolas que tive a oportunidade de observar: os alunos se declaravam incapazes de utilizar a Língua em contexto real alguns por falta de oportunidade, outros por falta de interesse. Em parte, a sensação de não aprender nada é reforçada pela carga horária: escolas que reservavam dois períodos semanais para a Língua Inglesa, a partir dos anos finais do Ensino Fundamental, com a inclusão (bem-vinda!) do Espanhol, da Filosofia e Sociologia, optaram, em sua maioria, por deixar apenas um período semanal. Para alguém cuja Língua Materna é o Português, consiste em relevante obstáculo a falta de continuidade que um único período semanal causa.

\section{Estabelecendo objetivos}

Entre 2008 e 2010, a autora deste artigo recebeu algumas turmas de Ensino Médio para lecionar Língua Inglesa. Diante das dificuldades já descritas, e traçando paralelos com os procedimentos adotados nas aulas de Língua Portuguesa (e

5 Cabe dizer que, como professora de Português, sempre ouvi elogios aos docentes de diversos componentes curriculares que utilizavam filmes e páginas da Internet como ferramentas para o aprendizado; no entanto, em todas as instituições pelas quais passei antes do CAp, o professor de Língua Estrangeira que se utilizava de mídias com certa frequência passava a ser 'vigiado', como se não estivesse dando aula. 
que a experiência indicava serem bem sucedidos), traçou alguns objetivos que poderiam auxiliar no ensino de Língua Inglesa:

- proporcionar situações de aprendizado nas quais os alunos teriam a oportunidade de encarar a Língua Estrangeira como uma abertura para outras culturas.

Ainda que pareça evidente para os profissionais da área e para o público esclarecido, a tendência de pais e alunos é tratar a LE como um componente curricular menor - o que parece atestado pela menor quantidade de períodos que lhe são concedidos, e pela sensação de não saber nada provocada pelas dificuldades com o vocabulário. Não se dá destaque suficiente ao acesso à diversidade cultural que o aprendizado de outra língua possibilita.

- contextualizar o vocabulário estudado

A maior parte dos alunos resiste ao aprendizado de Língua Inglesa porque se sente incapaz de aprender uma língua com um vocabulário tão diverso de sua Língua Materna. A compreensão do histórico de determinadas expressões deixa-o mais confiante, não apenas nos processos de recepção, mas nos de produção na LE.

\section{- possibilitar e estimular o writing}

$\mathrm{O}$ acesso à Internet faz com que o aluno tenha a oportunidade de ler em Inglês. Muitos jogos eletrônicos utilizam essa língua, e o vocabulário desses contextos de uso é aprendido velozmente pelas crianças e adolescentes. Utilizar esse conhecimento para a produção escrita efetiva é um passo adiante no processo de aprendizado de LE. 


\section{Quatro estratégias e seus efeitos}

A seguir, descrevemos quatro estratégias desenvolvidas nas turmas de Língua Inglesa sob nossa responsabilidade, relatando algumas das observações feitas.

\section{A aula inaugural}

Uma das propostas da escola em que fizemos nossas observações é a de que o professor realizasse uma espécie de aula inangural, no começo de cada ano letivo. Uma vez que meu trabalho na escola começou em setembro de 2008, eu estava dispensada de realizar tal atividade; no entanto, julguei apropriado, como professora nova na escola, que os alunos tivessem uma ideia sobre o que esperar das aulas de Língua Inglesa.

A aula foi planejada para ter dois momentos:

Momento 1: apresentação e confronto - depois de uma breve apresentação pessoal, a professora dizia saber que a maior parte dos alunos não gostava de ter aulas de Inglês, e que compreendia isso parcialmente. Admitia as dificuldades com o vocabulário, dando alguns exemplos no quadro, de palavras muito diversas daquelas do Português:

$$
\begin{gathered}
\text { Sky - céu } \\
\text { Cloud - nuvem } \\
\text { Dog - cachorro } \\
\text { Table - mesa }
\end{gathered}
$$

A seguir, chamava a atenção dos alunos para o fato de que todas essas palavras são relacionados a elementos do dia a dia e que termos, digamos, mais civilizados ou científicos eram mais longos e familiares:
Civilization
Education
University
Structure 
Esses elementos permitiam um breve histórico da Língua Inglesa, suas bases anglo-saxãs (que explicavam boa parte do vocabulário rotineiro) e seus traços latinos (vocabulário, aliás, admirado pelos falantes nativos, associado ao mundo acadêmico e a certo refinamento cultural).

Esse momento inicial fazia os alunos compreenderem que havia dois grupos vocabulares muito diferentes, dentro da Língua Inglesa, e que a busca por cognatos era efetiva, em especial se eles estivessem lendo textos técnicos.

Foi interessante notar que, tal qual em um processo psicanalítico freudiano (se me permitem a comparação), conhecer as prováveis causas das dificuldades serviu muito bem para tranquilizar os alunos, e era possível notar a postura mais receptiva, após essas observações ${ }^{6}$.

Momento 2: comparações sintáticas - a aula incluía uma comparação, no quadro, entre a conjugação verbal do presente do indicativo do verbo amar, em Português, com o presente simples do verbo To Love, a fim de mostrar que, nesse ponto, a Língua Materna era bem mais exigente.

A seguir, os alunos trabalhavam em grupo para formular sentenças simples utilizando o presente simples e vocabulário sugerido pela professora. Consistia em uma atividade bastante leve, em que os alunos deveriam montar frases a partir de uma tabela como essa:

\begin{tabular}{l|l|l}
\hline Subject & Verb & Object \\
\hline The man & Love & The egg \\
\hline The witch & Adore & The cat \\
\hline The dogs & Like & The car \\
\hline The duck & Prefer & The moon \\
\hline
\end{tabular}

6 Utilizamos o exemplo da Estátua da Liberdade, nessa aula inaugural: ela poderia ter sido chamada Statue of Freedom ou Statue of Liberty. A escolha foi pelo termo de origem latina - o que facilita a vida dos falantes de línguas latinas. 
Montadas, digamos, dez frases, os alunos deveriam escolher cinco delas e inventar histórias que terminassem com as sentenças. As histórias poderiam ser em Língua Portuguesa, obviamente, e deviam contextualizar adequadamente a frase escolhida. Foi oferecido um exemplo, com a frase The man loves the egg:

É dia do aniversário do homem. Ele achou que todos haviam esquecido; no entanto, quando ele chega em casa do trabalho, sua esposa havia feito uma refeição especial, e fritado um ovo exatamente do jeito que ele gosta. Ela lhe dá os parabéns e ele se senta à mesa para comer, muito feliz. Naquele momento, the man loves the egg.

As turmas, independentemente da série - e essa atividade foi utilizada como sondagem para as três séries do Ensino Médio - gostavam muito da atividade. Os pontos positivos eram a possibilidade montar sentenças completas, ainda que simples, e utilizá-las em contextos narrativos relativamente complexos. A sensação de montar uma frase gramaticalmente correta e com contexto adequado era uma alavanca importante para aquelas turmas. Os debates em grupo eram bastante interessantes, e a circulação pela sala permitia o esclarecimento de dúvidas, tal como o acréscimo de $S$ à terceira pessoa do singular, as formas possíveis de alteração dos itens da tabela (inversão de sujeito e objeto e suas consequências para o sentido da oração, uso de plural, etc). a atividade também proporcionou um paralelo positivo com os conceitos de sujeito e objeto, estudados em Língua Portuguesa, e reforçou a presença importante de cognatos e termos já familiares.

\section{As Cores e seus Significados}

Foi planejada uma aula de listening para os alunos, em momento posterior do ano letivo. 
A atividade consistia em a professora fazer uma fala em Língua Inglesa, colocando as palavras-chave do que era dito no quadro, e estimulando os alunos a exprimirem o que estavam entendendo em voz alta, na língua materna. Assim, à medida em que a palestra prosseguia, a turma ia se ajudando para construir o conteúdo da fala.

O tema eram os diferentes sentidos das cores em diferentes culturas, dando destaque para a língua Inglesa, obviamente. Nessa aula os alunos ficavam sabendo de associações como blue e sadness, green e jealousy, red and sexyness, yellow e cowardice. A maior parte dos alunos desconhecia essas relações, e todos ficavam muito surpresos ao ouvirem sobre a história do Blues, e sobre a origem shakespereana da relação entre verde e ciúme. Houve diversas contribuições, em especial no que diz respeito à utilização do vermelho para sinalizar uma femme fatale em filmes e séries de TV.

Normalmente, além de apreciarem a aula por ser diferenteconceito aplicado pelos alunos de forma positiva - havia muitos comentários a respeito do ineditismo dos conceitos apresentados. Certamente, essa aula acrescentava muito ao conhecimento linguístico e cultural dos alunos, e tornava-os capazes de ressignificar uma série de experiências visuais relacionadas a produções midiáticas em Língua Inglesa, que antes não possuíam sentido específico.

\section{Expressões de amor}

Um dos pedidos freqüentes dos alunos, em aula de LE, é o trabalho com música. Normalmente o que os motiva é a curiosidade sobre canções pop, muitas vezes estimulada pelos vídeo-clipes, que há alguns anos ocupam espaço preferencial em alguns canais de televisão.

Ao realizar uma pesquisa para descobrir músicas que contivessem determinados pontos gramaticais (seguindo assim uma das tradiçôes no uso de música na sala de aula), notou-se que a 
maior dificuldade dos alunos não estaria no ponto gramatical a ser observado, mas nas expressões idiomáticas. Por essa razão, foi montada uma lista de expressões da língua inglesa relacionadas ao amor, algumas canções foram selecionadas, e a aula foi montada para que os alunos se dessem conta da freqüência com que determinadas imagens e metáforas apareciam.

Foram utilizados agrupamentos de expressões, de acordo com a temática utilizada. Um dos itens, Estações do Ano, rendeu muitos comentários a respeito das diferenças na intensidade e nos meses do ano, das estações no Brasil e na maioria dos países de Língua Inglesa. Os alunos reconheceram trechos de canções que utilizavam metáforas relacionados ao verão para a paixão, ao inverno para a separação, à primavera para o namoro e ao outono a nostalgia.

Outros itens em destaque foram as expressões ligadas ao jogo (cheat, loose, game, queen, king, joker), as manifestações de sofrimento amoroso (tears, sorrow, crying), os termos doces e leves (baby, sugar, sweetheart) e os fenômenos da natureza (o sol como calor e alegria, a lua como mistério, o vento que sussurra o nome do ser amado, as montanhas e rios como obstáculos, etc). A atividade seguinte envolvia escrever uma carta de amor, em Inglês, utilizando os chavões estudados. A carta poderia ser sincera ou irônica - cabia aos alunos decidirem.

Houve também um momento de pronúncia, no qual os alunos foram capazes de reconhecer as expressôes que mais ouviam em músicas; muitos chegaram a contribuir com termos para as listas, com base em canções que eles conheciam, e a professora, não.

\section{A Literatura em alta}

Entendo aqui por humanização [...] o processo que confirma no homem aqueles traços que reputamos essenciais, como o exercício da reflexão, a aquisição do saber, a boa disposição para com o próximo, o afinamento das emoçôes, a capacidade de penetrar nos problemas da vida, o senso 
da beleza, a percepção da complexidade do mundo e dos seres, o cultivo do humor. A literatura desenvolve em nós a quota de humanidade na medida em que nos torna mais compreensivos e abertos para a natureza, a sociedade, o semelhante (CÂNDIDO, 1995, p. 249).

Um pouco mais ousada do que as atividades mencionadas anteriormente $^{7}$ foi a inclusão da Literatura de Língua Inglesa nas aulas para o Ensino Médio. Foram programadas três aulas, a serem ministradas em momentos bem diferentes do ano letivo:

- Beowulf, aula que proporcionava estudos de vocabulário bastante específicos, com termos para território, divindades (a relação dos nomes dos dias da semana com a mitologia Nórdica) e adjetivos para os personagens do livro, colocando em destaque que os adjetivos escolhidos pelos alunos representam a forma como eles julgam os personagens.

- Ciclo Arthuriano, aula que permitia partir das relações corteses típicas da Idade Média, dos códigos de honra (courage, faith, loyalty, chivalry), entre outras referências (prince charming, the quests for the Holy Graal, the Round Table) e elementos do mundo medieval que ainda marcam o vocabulário do Inglês moderno (como fair e lady). Em especial, a difusão de várias versôes para as lendas arthurianas possibilitam uma interessante associação entre pesquisa na Internet, livros e filmes, e a montagem de mapas conceituais, nos quais os alunos poderiam associar de diferentes maneiras os personagens marcantes das lendas pesquisadas.

- Shakespeare, aula nas quais se pode partir de citações famosas e referências culturais marcantes (as bruxas de Macbeth, as filhas do Rei Lear, a cena do balcão de Romeu e Julieta, os coveiros de Hamlet), para estabelecer algumas das ideias que movem as tramas. What's in a name?, A rose by any other name, To be or not to be são alguns dos elementos que, colocados em contexto, ganharam significação para os alunos ${ }^{8}$.

\footnotetext{
Utilizo o termo ousada porque há resistência explícita por parte de Orientação Pedagógica e Supervisão de diversas escolas, essa inclusão da Literatura de Língua Estrangeira nos conteúdos de série.

8 O verbo to be, tão espezinhado, ganhava um novo alento, ao estar associado a uma das frases aparentemente mais simples e, no entanto, mais cheias de possibilidades reflexivas da Literatura Universal.
} 
Além dos evidentes ensejos para debates e troca de informações, essas aulas de Literatura tinham o objetivo de oportunizar situações de interpretação das obras, produzindo redes de palavras relacionadas entre si e adequadas à leitura das mesmas. Os alunos percebiam, ao longo das atividades, quão carregadas de significado determinadas palavras de um idioma podem estar, aos ouvidos daqueles que estão envoltos em seu ambiente cultural.

\section{Conclusão}

O ensino brasileiro tem sofrido uma série de reformulações, nas últimas décadas. A maioria delas privilegia o tratamento interdisciplinar dos assuntos estudados e resgata a importância de componentes curriculares que poderiam ser deixados para trás na atual sociedade, que privilegia a tecnologia em detrimento de valores humanistas. Em termos gerais, ainda que estejam em teste e/ou debate, nota-se o esforço em busca da qualificação das práticas de sala de aula.

No entanto, ainda há muito o que fazer a fim de superar questốes estruturais: o simples fato de haver apenas um ou dois períodos semanais para o ensino de Língua Estrangeira é evidência de que as pretensões de quem está pensando o ensino brasileiro não podem ser ainda concretizadas adequadamente.

Por enquanto, o que é possível fazer para atenuar essa falta de tempo é o aproveitamento de cada aula para a criação de um ambiente de aprendizado que dê conta de diferentes aspectos da língua. A utilização de elementos culturais como apoio para o aprendizado de vocabulário nos parece uma alternativa adequada, dentro do atual contexto.

É evidente que não se pode comparar o conhecimento cultural a respeito de seu próprio contexto, do aluno falante de Língua Portuguesa, com o conhecimento produzido em uma sala de aula, a partir de propostas como as descritas acima. No entanto, a facilidade de acesso às mídias eletrônicas pode auxiliar 
na construção desse ambiente - é notável que a experiência cultural dos alunos é ampla, e pode ser aproveitada como elemento de construção de novos significados.

$\mathrm{O}$ aprendizado de Língua Estrangeira pode e deve se tornar uma experiência de abertura para outras culturas, outras realidades, outros espaços de vivência. Língua Materna e Língua Estrangeira são adequadas a essa missão, e acreditamos que podem melhor atuar à medida em que não permitam muros e gavetas cerceando-lhes a riqueza que podem criar.

\section{Referências}

BRASIL. Parâmetros Curriculares Nacionais: Ensino Médio. Brasília: MEC/ Semtec, 2002.

CANDIDO, Antonio. O direito à literatura. In: Vários escritos. $3^{\mathrm{a}}$ ed. São Paulo: Duas Cidades, 1995.

MELO NETO, João Cabral de. Obra completa: volume único. Rio de Janeiro: Nova Aguilar, 1994. 